\title{
The role of endoscopy in the management of postoperative patients with Crohn's disease
}

\author{
Brian Bressler MD MS FRCPC
}

$\mathrm{D}_{\mathrm{R}}$ espite the best efforts of both the physician and the patient, a certain proportion of patients with Crohn's disease (CD) will inevitably need to undergo an operation for the management of their disease. The literature suggests that approximately $75 \%$ of patients with $\mathrm{CD}$ will require at least one resection in their lifetime (1). Surgical resection is a pivotal event in the patient's disease because it potentially marks an occasion to 'reset the clock' to the time where none or a very minimal amount of the inflammation is present in the area of the patient's small bowel or colon, which was previously affected with CD. Therefore, after recovering from the operation, most patients feel the healthiest they have felt in a long time. Due to this fact, and because the gastroenterologist may have taken a more distant role in the management of the patient because the surgeon has become more involved, this event may unfortunately lead to a parting of ways between the gastroenterologist and the patient, which would be appropriate if the

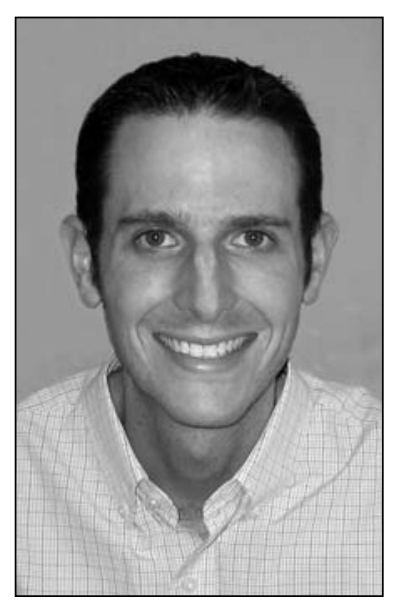

Dr Brian Bressler

study (2), 89 patients who had ileal resections between 1979 and 1984 were followed to evaluate the natural history of early postoperative endoscopic lesions. Eighty-two of these patients received a colonoscopy with examination of the neoterminal ileum within one year after surgery. At ileocolonoscopy, ileal lesions were scored as followed: IO - no lesions, I1 - fewer than five aphthous lesions, I2 - more than five aphthous lesions with normal mucosa between the lesions, or skip areas of larger lesions confined to the ileocolonic anastamosis (less than $1 \mathrm{~cm}$ in length), I3 - diffuse aphthous ileitis with diffusely inflamed mucosa and I4 - diffuse inflammation with already large ulcers, nodules and/or narrowing. Seventy-three per cent of these patients had endoscopic evidence of recurrent disease within one year of surgery, but only $20 \%$ of these patients had recurrent symptoms. Three years after surgery, the endoscopic recurrence rate was $83 \%$ and the symptomatic operation was a cure for CD. Unfortunately, no such cure exists. Three years after surgical resection, $85 \%$ of all patients will have signs suggestive of recurrent CD (2). Furthermore, within 15 years, more than $70 \%$ of patients will require a second operation (1). This predicted high recurrence rate, along with other ongoing issues relating to patients with $\mathrm{CD}$, emphasizes the importance of maintaining a close follow-up of these patients.

Because of the progressive nature of this condition, different prophylactic medications have been studied to prevent recurrence of CD (3). Unfortunately, none of the medications studied have shown suitable clinical efficacy and tolerability; therefore, a current recommended therapy for prevention of postoperative recurrence of $\mathrm{CD}$ is lacking. Due to this void in our treatment regimen for $\mathrm{CD}$, identifying those patients who are most likely to have recurring disease and offering them prophylactic treatment is an important strategy. Many studies have focused on finding predictors of recurrent disease. Patient characteristics (ie, smoking [4-6] and perianal disease [7]), surgical techniques (stapled anastamosis [8]) and histological characteristics (granulomas [9] and myenteric plexitis [10]) have all been suggested to identify those patients most likely to have recurrence of the disease. However, the quality of many of these studies limits the reliability of these findings, and studies have also shown that many of these factors do not predict recurrent disease.

Endoscopic evidence of recurrent $\mathrm{CD}$ has been shown to predict clinically symptomatic CD (2). In a prospective cohort recurrence rate was $34 \%$. Various clinical characteristics were analyzed in this study, and the best predictor of symptomatic recurrence of $\mathrm{CD}$ was endoscopic recurrence. There was a significant correlation between the extent of recurrent disease, as assessed by this endoscopic scoring system, and the chance of symptomatic recurrence. There was a strong, statistically significant increased risk of developing symptomatic recurrent $\mathrm{CD}$ if the patient had I4 or I3 lesions compared with either IO or I1 lesions ( $\mathrm{P}=0.0001$ for both comparisons).

This study provided very important information relating to how patients with CD should be followed postsurgical resection. First, the results have proved that the vast majority of patients will have endoscopic recurrence of $\mathrm{CD}$ within three years following surgical resection. Although previously appreciated, the fact that only $34 \%$ of patients had symptomatic recurrent disease demonstrates that endoscopic evidence of active disease does not necessarily correlate with patient symptoms. However, the assessment used in this trial of recurrent disease has not been validated. In fact, the assessment of clinical recurrence after surgical resection of $\mathrm{CD}$ varies among many of the different therapeutic trials examining treatment for medical prophylaxis of CD postsurgical resection; this discrepancy must be addressed in future trials evaluating this patient population. Regardless of this limitation, endoscopic recurrence is clearly an important predictor of clinical recurrent $\mathrm{CD}$.

Colonoscopy with careful examination of the neoterminal ileum is an important diagnostic tool that I use in following

Department of Gastroenterology, St Paul's Hospital, Vancouver, British Columbia

Correspondence: Dr Brian Bressler, Department of Gastroenterology, St Paul's Hospital, 1081 Burrard Street, Vancouver, British Columbia

V62 1Y6. Telephone 604-688-6332 ext 222, fax 604-689-2004,e-mail brian_bressler@hotmail.com 
patients with CD after surgical resection. I recommend that all patients be considered for a colonoscopy six months to one year after their surgery. Following this colonoscopy, I consider additional colonoscopy surveillance based on the endoscopic findings and the patient's previous clinical course of disease before their resection. As previously mentioned, because the data on postoperative prophylaxis medical treatment for CD does not suggest a particularly effective and tolerable strategy, every patient should not be placed on medical therapy after their resection. However, ileocolonic examination for the purpose of evaluating the presence of recurrent CD addresses two important considerations. First, those with evidence of severe recurrent disease (I3 or I4 lesions) are patients more likely to have clinical recurrent disease. Therefore, these patients would most likely benefit from treatment (such as azathioprine) before experiencing symptoms. Second, documenting mucosal disease to those patients in whom one would consider starting prophylactic treatment is important, particularly when the decision is to introduce immunosuppressive therapy. Compliance in this group of patients is a particular challenge; in many instances these patients feel better than they have for a long period of time because before their operation they were failing medical therapy. This current way of practice has not been evaluated in a controlled trial setting. Proper clinical trials evaluating this strategy are required to determine if the medications that have been suggested to be effective in the prevention of recurrence would work in this cohort of patients, and at what degree of endoscopic recurrence is it appropriate to intervene. Other more sensitive methods for evaluating the small bowel (ie, capsule studies) may theoretically lead to improved compliance; however, they

\section{REFERENCES}

1. Mekhjian HS, Switz DM, Watts HD, Deren JJ, Katon RM, Beman FM. National Cooperative Crohn's Disease Study: Factors determining recurrence of Crohn's disease after surgery. Gastroenterology 1979;77:907-13.

2. Rutgeerts P, Geobes K, Vantrappen G, Beyls J, Kerremans R, Hiele M. Predictability of the postoperative course of Crohn's disease. Gastroenterology 1990:99;956-63.

3. Penner RM, Madsen KL, Fedorak RN. Postoperative Crohn's disease. Inflamm Bowel Dis 2005;11:765-77.

4. Cottone M, Rosselli M, Orlando A, et al. Smoking habits and recurrence in Crohn's disease. Gastroenterology 1994;106:643-8.

5. Lindberg E, Jarnerot G, Huitfeldt B. Smoking in Crohn's disease: Effect on localization and clinical course. Gut 1992;33:779-82.

6. Moskovitz D, McLeod RS, Greenberg GR, Cohen Z. Operative and environmental risk factors for recurrence of Crohn's disease. Int J Colorectal Dis 1999; 14:224-6. have not been studied extensively in the postoperative arena. Although resources in many areas for endoscopic examinations are limited, the aggressive treatment of specific patients with CD may have a positive benefit on subsequent resource utilization if symptomatic relapses can be prevented.

A final role of colonoscopy which should not be overlooked in this patient group, is in those individuals who previously had both small bowel and significant colonic involvement (more than one-third of their colon affected based on endoscopic examination) before their resection. Provided the portion of the colon with previous evidence of active $\mathrm{CD}$ remains, they require typical endoscopic dysplasia surveillance after they had had their disease for at least 10 years. The appropriate way to perform endoscopic dysplasia surveillance has been previously reviewed (11).

As we continue to improve our understanding regarding the etiology of $\mathrm{CD}$, our therapy for CD improves. These accomplishments have allowed investigators to begin to use mucosal healing as an achievable end point in clinical studies. Although mucosal healing as a guide to treatment response is not yet ready to be used in clinical practice, the evaluation of mucosal disease in patients with CD who have had a surgical resection should be considered. This method of following this particular cohort of patients may interrupt the progressive disease course of patients with $\mathrm{CD}$ who require surgical resection for therapy by introducing possibly effective medical prophylaxis. Furthermore, this method may limit the exposure of medical therapy to patients with no endoscopic evidence of recurrence in whom the benefit for treatment maybe minimal, and they would be spared potential toxicity from these medications.

7. Greenway SE, Buckmire MA, Marroquin C, Jadon L, Rolandelli RH. Clinical subtypes of Crohn's disease according to surgical outcome. J Gastrointest Surg 1999;3:145-51.

8. Heimann TM, Greenstein AJ, Lewis B, Kaufman D, Heimann DM, Aufses AH Jr. Prediction of early symptomatic recurrence after intestinal resection in Crohn's disease. Ann Surg 1993;218:294-8; discussion 298-9.

9. Anseline PF, Wlodarczyk J, Murugasu R. Presence of granulomas is associated with recurrence after surgery for Crohn's disease: Experience of a surgical unit. Br J Surg 1997;84:78-82.

10. Ferrante M, de Hertogh G, Hlavaty T, et al. The value of myenteric plexitis to predict early postoperative Crohn's disease recurrence. Gastroenterology 2006;130:1595-606.

11. Panaccione R. The approach to dysplasia surveillance in inflammatory bowel disease. Can J Gastroenterol 2006;20:251-3. 


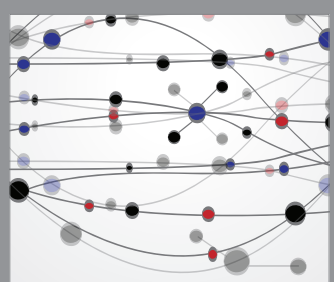

The Scientific World Journal
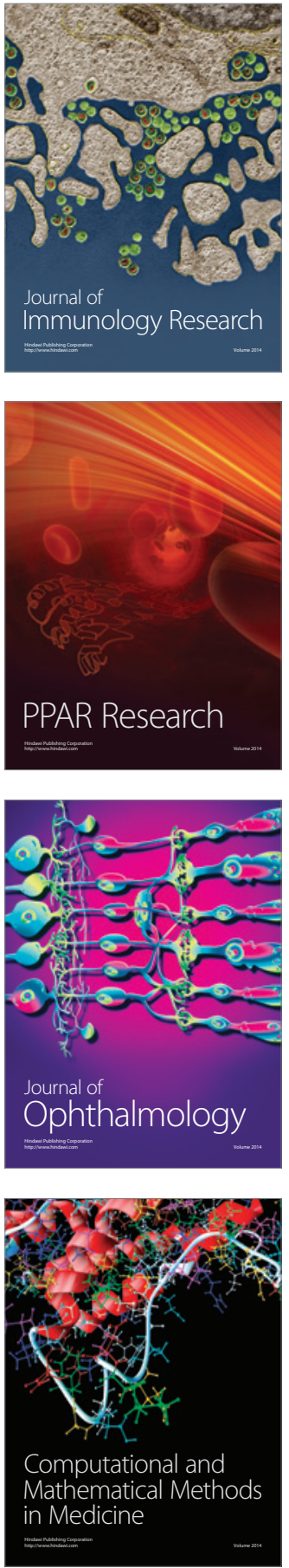

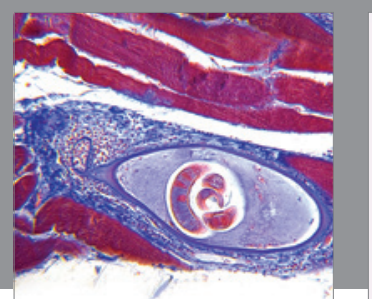

Gastroenterology Research and Practice

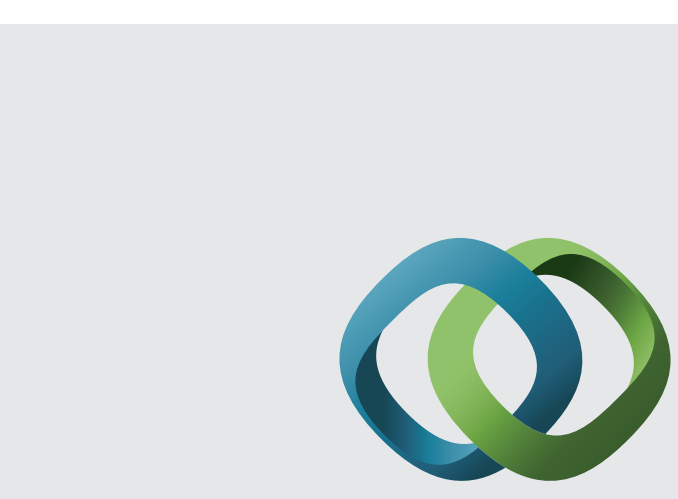

\section{Hindawi}

Submit your manuscripts at

http://www.hindawi.com
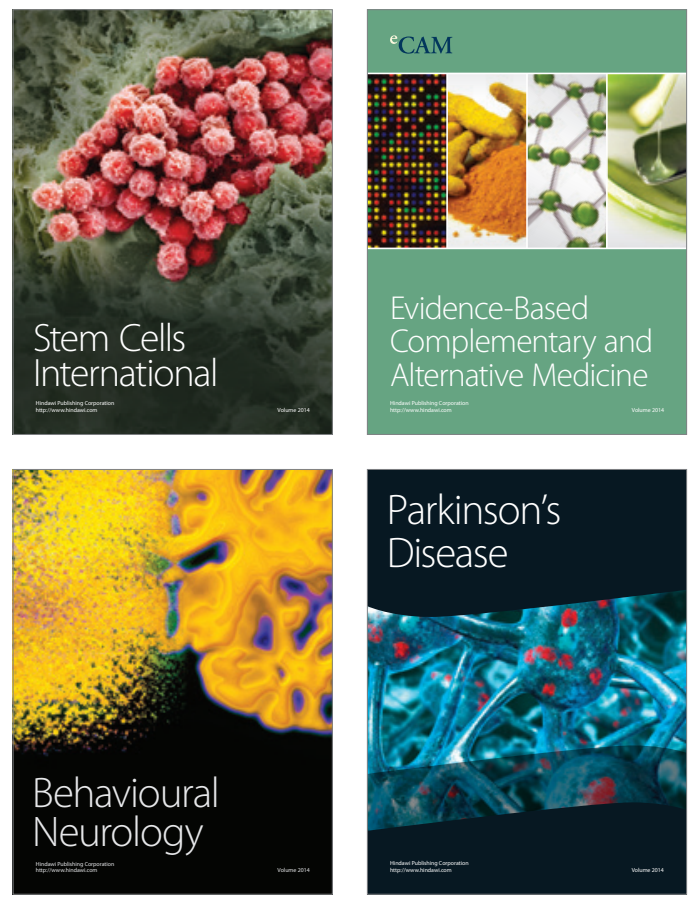
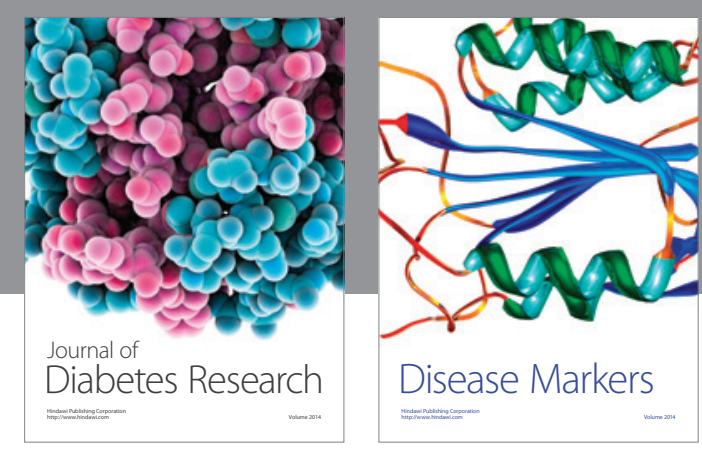

Disease Markers
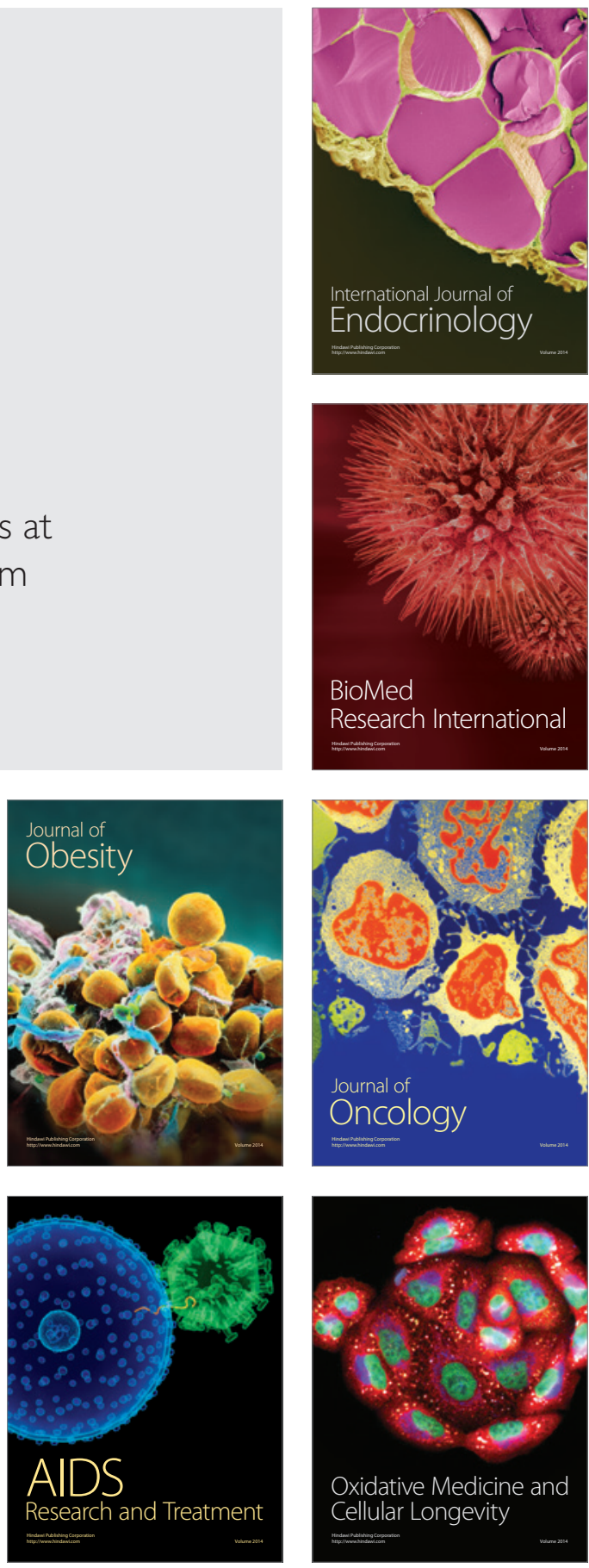